\title{
Psychosocial Predictors of Acculturative Stress among Female and Male Immigrant Asian Americans: A Gender Comparison Study
}

\author{
Sanrong Xiao ${ }^{1,}$ i, Ranran $\mathrm{Liu}^{2}$, Kang $\mathrm{Yao}^{1}$, and Ting Wang ${ }^{2, *}$ \\ ${ }^{1}$ School of Sports and Education, Nanchang University, 330031 NanChang, China \\ ${ }^{2}$ School of Humanities, Jiangxi University of Traditional Chinese Medicine, 330004 NanChang, China
}

\begin{abstract}
The purpose of this study was to examine whether gender differences existed and how the predictors were linked to acculturative stress across gender among a national sample of 1639 immigrant Chinese, Filipino, Vietnamese, and other Asian Americans. The data were from the National Latino and Asian American Study (NLAAS) conducted in 2002 and 2003, the first national epidemiological household survey of Asian Americans in the United States. The participants took part in face-to-face interviews, which were conducted with computer-assisted interviewing software in Mandarin, Cantonese, Tagalog, Vietnamese, and English. After fitted bivariate correlations to examine the relationships between acculturative stress and psychosocial variables, data were analyzed using two multiple regressions to identify the most significant predictors of acculturative stress for men and women separately. Results indicated that the psychosocial predictors of acculturative stress varied with gender status. For all men and women, longer years in the U.S., higher English proficiency, and less perceived discrimination predicted related to less acculturative stress. Social network was not the predictor for both men and women. Age of immigration, marital status, family cohesion and social position were additional significant predictors of acculturative stress only for men, but not for women. The implications of these results were discussed.
\end{abstract}

\section{INTRODUCTION}

Many immigrant children and families experience acculturative stress, but few relevant empirical studies on psychosocial predictors of the stress have been conducted,especially among immigrant Asian Americans. In these limited literature, scholars have demonstrated that several sets of factors linked to acculturative stress included socio-demographic factors such as age, gender, social networks, family cohesion and the context of migration exit; immigration related factors such as age of immigration; psychological factors such as depression; Linguistic factors such as English proficiency, native language proficiency and Language preference; and receptivity by the host society such as discrimination. ${ }^{[1-3]}$ However, previous studies often fail to consider that men and women experienced acculturative stress very differently. ${ }^{[4]}$ And less prior studies have examined whether acculturative stress is associated with one factor more than others or whether it is the combination of factors that best explains acculturative stress for immigrant American men and women.

There is a call for more research on acculturative stress among Asian immigrants because Asian Americans are one of the most rapidly growing ethnic groups in the United States, and high number of Asian immigrants experience acculturative stress. ${ }^{[5]}$ Therefore, this study aims to test whether gender differences exist in how the psychosocial predictors are linked to acculturative stress among a nationally representative sample of Asian immigrants in the United States.

\subsection{Acculturative Stress in Asian Americans}

Acculturative stress is defined as a marked deterioration of psychological, somatic, and social aspects of health, ${ }^{[1]}$ which is thought to be a possible result accompanying the process of acculturation among immigrants and later generations of ethnic minority individuals or groups. Adaptation to a new culture can be very difficult and stressful because of possible changes in identity, values, behaviors, cognitions, and attitudes. ${ }^{[7-9]}$ Acculturative stress has a pervasive, life-long influence on psychological adjustment, decision-making abilities, occupational functioning, and physical health. ${ }^{[9]}$ It is typically related to symptoms of anxiety and depression, which may increase if the individuals lack of an effective social support system. ${ }^{[10]}$ Studies suggest that acculturative stress is a more proximal risk factor of mental health problems and increase risk for mental health problems independently of global perceptions of stress. ${ }^{[11]}$ The degree of acculturative stress experienced by an individual can range from mild stress, which gradually improves as the individual adapts, to a debilitating stress that worsens over time. ${ }^{[1][12-14]}$

\footnotetext{
* Corresponding author: Ting Wang, E-mail:125323611@qq.com
} 
Research of acculturative stress has shown that a substantial number of immigrant children and families experiencing acculturative stress, although the level of difficulties have varied widely among them. ${ }^{[15]}$ Uppaluri et al. found that Asian immigrants have a tendency of underreporting with regards to acculturative stress. ${ }^{[5]}$ An empirical study reported high number $(70 \%)$ of Asian Americans experiencing acculturative stress according to one of the results from the National Latino and Asian American Study (NLAAS). ${ }^{[3]}$ International migration is considered to be one of the most significant stressful life events in one's life, and is often described as an ecological term of "uprooting experience". The core experience of international migration, sudden changes in many areas of a person's life (e.g., socio-economic status, social networks, family structure and function) within a shorter period of time and the subsequent adaptation process often causes or exacerbates his or her stress. ${ }^{[16-18]}$

The early 1970s findings suggested that culture contact and change led to stress, ${ }^{[19]}$ and emphasized the inevitability of negative psychological consequences of acculturating such as emotional distress, shock, and anxiety. ${ }^{[20]}$ Contemporary empirical investigations tend to support the multiple contributors of acculturative stress. ${ }^{[21]}$ For example, immigrants who feel marginalized and maintain a separation from both their ethnic culture and the host culture tend to be highly stressed. ${ }^{[16]}$

Studies also find that social support activities reduce the level of acculturative stress; social support moderate and buffer the effect of acculturative stress on mental health symptoms, and the effect of support is mainly or exclusively present when there is a high level of acculturation to American language and interpersonal associations. ${ }^{[22]}$ Social support had both a positive and a negative impact on alcohol use across Asian immigrants depending upon which acculturative stressor was examined. ${ }^{[23]}$

Support from parents and perceived family conflict are the most important predictive factors in determining the level of acculturative stress. ${ }^{[24]}$ Studies on Asian Americans also show that family cohesion is a predictor of acculturative stress, ${ }^{[3]}$ more family conflicts and less family cohesion could predict higher acculturative stress $^{[25]}$. Park revealed that support from friends was found to have a significant role in mediating between acculturative stress and depression. ${ }^{[26]}$

Similarly, findings revealed that the main source of acculturative stress was related to concern over English language proficiency, issues of parental control and conflicting cultural rules. ${ }^{[27]}$ English language proficiency is one of the strongest predictors of acculturative stress among Asian immigrants. ${ }^{[32]}$ English language usage imposes the greatest discrimination barrier to all non-American cultures ${ }^{[28]}$. English proficiency may serve as a marker for the ability of immigrants to move outside of their immediate social circles and expand their opportunities for education, employment and other types of social and economic resources. $^{[29]}$ So inability to speak English fluently can negatively affect acculturation of immigrants.

Specifically, discrimination is a major source of acculturative stress in immigrants and ethnic minorities. ${ }^{[29]}$ Researchers have shown that increased levels of discrimination led to increased acculturative stress in Asian immigrants. ${ }^{[32]}$ Other studies have also confirmed the links between acculturative stress and perceived discrimination. ${ }^{[30-31]}$ Mak and Nesdale found the immigrants' perceptions of discrimination were associated with higher psychological distress, even after coping resources and gender had been controlled. ${ }^{[32]}$

In addition, studies have confirmed the links between marital status and acculturative stress. For example, Duru and Poyrazli found that the single international students are less likely to experience acculturative stress than are married students. ${ }^{[33]}$ Other research also showed that "married or cohabiting" status could predict higher acculturative stress in Asian immigrants. ${ }^{[32]}$

Much evidence has shown that a person's age of immigration could influence acculturation proceeds. Berry revealed that this process is generally smoother if a person arrives when he or she is very young (i.e., pre-school) rather than when an adolescent or older adult (e.g., retirement or joining one's children ${ }^{[34]}$. Scholars suggested that immigrants who migrated after the age of 14 experienced greater acculturative stress than individuals who migrated before age 14. ${ }^{[35]}$ Age of immigration can be seen as a measure of the developmental context in which immigrants arrive in this country. A study of Chinese Americans also included number of years in the United States in their hierarchical multiple regression, but this variable was never significant. ${ }^{[36]}$

\subsection{Acculturative Stress and gender socialization}

Although issues of gender have traditionally been ignored or distorted in the mental health literature, the forces are now increasingly recognized as powerful influences on many aspects of human development ${ }^{[37]}$. Researchers have highlighted the disparity in gender socialization experiences for immigrant men and women. However, the gender with acculturative stress relationship has been conducted partial or mixed results in immigrants. ${ }^{[14]}$ For example, some studies have affirmed that acculturative stress differ across gender ${ }^{[1][36[38]}$; whereas other studies have indicated that it does not. ${ }^{[39]}$

Berry and his colleagues suggested that female migrants may be more at risk for problems during the acculturation process because "attempts to take on new roles available in the society of settlement may bring them into conflict with their heritage culture". But they also pointed out that it was not evident from the studies they cross-compared and also from previous research whether there actually is greater acculturative stress levels for women and girls, or whether this is influenced by other social aspects and situations. Consistent with this conclusion, other studies also find gender has a significant impact on predicting acculturative stress ${ }^{[1][36]}$, and moderates the effects of stress among immigrants ${ }^{[40]}$. Aranda et al.reported that stress stemming from the family or cultural conflict has been related to depressive 
symptoms in immigrant women only, whereas social marginalization has only been related to symptoms of depression and anxiety in immigrant men. ${ }^{41]}$

On the other hand, several empirical studies of Asian Americans suggest limited support for this proposition. As Ying noted in his study of Taiwanese students living in the United States, whether acculturative stress varies between Asian male and female immigrants is inconclusive. According to Lueck and Wilson's results, gender is eliminated in the second step of regression model selection $(P=0.5262){ }^{[42]}$

These inconclusive limits have indicated that it is necessary to pay attention to nuances of acculturative stress. Available evidence suggested that the correlates might affect acculturative stress differently for female and male. Beiser et al. revealed several of the variables which increase acculturative stress affect female immigrants more than their male counterparts. ${ }^{[43]}$ The risk factors such as separation from family members, marital status, and support network can affect immigrant men and women's stress differently at the time of migration, because women from traditional cultures tend to be more fully enmeshed in family networks than men and more devastated by their absence. In general, females are more vulnerable than males to interpersonal stressors, and males more unprotected when experiencing stress related to achievement. ${ }^{[44]}$ Moreover, some scholars found that gender contributed significant variance to the self-reported sympathy. Sympathy mediated the relationship between acculturative stress and prosocial tendencies for men only, but not for women. ${ }^{[45]}$

In sum, being aware of gender differences concerning social issues could infer that acculturative stress differs across gender. So studies of the differences of men and women's acculturative stress with respect to its psychosocial predictors are needed. However, less formal hypotheses were made regarding gender differences in the psychosocial predictors of acculturative stress among immigrants.

\subsection{Hypotheses}

Given that previous research has reported the gender differences in the risk factors of acculturative stress among immigrants, we examined whether gender differences existed and how the predictors were linked to acculturative stress across gender among Asian American immigrants. This study is another step in the direction toward the psychosocial predictors (years in the U.S., age of immigration, marital status, social position, English proficiency, discrimination, family cohesion and social networks) of acculturative stress in a nationally representative sample of Asian immigrants. This study aims to discover which psychosocial variables have more predictive impact on acculturative stress for women comparing with men. We hypothesized that gender differences will exist in the predicting effects on acculturative stress among Asian immigrants. Gender differences in predicting acculturative stress are expected such that several predictors will have a significant impact on women's acculturative stress only, whereas other factors will only be the strongest predictors of men's acculturative stress.

Informed by the review of previous research, the variables of years in the U.S., English proficiency, and discrimination are the most important and strongest predictors of acculturative stress among immigrants. And there is less evidence has shown that these variables have different predictive impact on acculturative stress across gender. Thus, we expect that years in the U.S., English proficiency, and discrimination will predict acculturative stress for both men and women.

The variables related to achievement, social position and social marginalization appeared to relate acculturative stress in immigrant men only. We expect to examine age of immigration, marital status, and social position will predict acculturative stress only for men. ${ }^{[41][44]}$

Furthermore, acculturative stress stemming from the family conflict or support network have been reported to affect female immigrants more than their male counterparts, even affect female only. ${ }^{[41][43]} \mathrm{We}$ expect that family cohesion and social networks will predict acculturative stress only for women.

\section{METHODS}

\subsection{Design and Procedures}

The data were from the NLAAS conducted by trained interviewers between May 2002 and November 2003. The study was part of a broader project, the Collaborative Psychiatric Epidemiology Studies (CPES), National Comorbidity Survey Replication (NCS-R), and the National Survey of American Life (NSAL). The NLAAS core sampling procedure resulted in a nationally representative household sample of Latino and Asian Americans who were 18 years or older and resided in any of the 50 states and Washington, D.C. , The three national origin groups targeted for the immigrant Asian American sample were Chinese, Filipino, or Vietnamese, but individuals of "other" Asian ancestry were also included.

A detailed description of the NLAAS protocol and sampling procedure has been previously documented ${ }^{[46-47]}$. In brief, it included the following three stages: (1) Core sampling in which primary sampling units (PSUs), defined as metropolitan statistical areas (MSAs) or county units, and secondary sampling units (SSUs), formed from contiguous groupings of Census blocks, were selected using probability proportionate to size (PPS), from which housing units and household members were sampled; (2) high-density supplemental sampling was used to over-sample Census block groups with greater than $5 \%$ density of target ancestry groups (Latino: Cuban, Mexican, Puerto Rican; Asian: Chinese, Filipino, Vietnamese). Individuals of Asian or Latino ancestry who did not belong to the target groups under which these geographical areas were classified were still eligible to participate. Thus, participants in high-density communities (i.e., with greater than $5 \%$ density of target 
groups) actually had two opportunities for NLAAS recruitment: first through the core sampling strategy and second through the high-density sampling strategy; and (3) further, second respondent sampling was used to recruit participants from households in which one eligible member had already been interviewed. Weighting corrections were developed to take into account the joint probabilities for selection under the three components of the NLAAS sampling design.

Response rates were achieved for Asian American first and second respondents, respectively. Weighted response rates were $69.3 \%$ for primary respondents, $73.6 \%$ for second adult samples, and $65.6 \%$ for final combined samples. Detailed sample characteristics are reported in other NLAAS studies. ${ }^{[46-47]}$ Participants were initially contacted with an introductory letter and study brochure, followed by screening, scheduling, and interviewing. Interviews were conducted using computer-assisted interviewing software, and were administered by trained bilingual interviewers with linguistic and cultural backgrounds similar to those of the target population. Face-to- face interviews were conducted with participants in the core and high-density samples, unless the respondent specifically requested a telephone interview, or if face-to-face interviewing was prohibited. The median length of the interview was 2.4 hours. As a measure of quality control, a random sample of participants with completed interviews was re-contacted to validate the data.

Coding Immigrants. Immigrants were classified as using one question "In which country were you born? the United States or other country?" on the NLAAS survey. Participants who reported "other country" were classified as belonging to immigrants.

\subsection{Sample}

Of the 2,095 Asian Americans in NLAAS, the present study examined 1,639 participants including 473 (28.9\%) Chinese, 349 (21.3\%) Filipino, 502 (30.6\%) Vietnamese, and $315(19.2 \%)$ other Asians with a mean age of 42.48 years $(S E=0.35)$ ranging from 18 to $95,868(53.0 \%)$ of the participants were women and 771(47.0\%) were men.

\subsection{Measures}

The NLAAS instruments were available in English, Spanish, Mandarin, Cantonese, Tagalog, and Vietnamese, and translated using standard translation and back-translation techniques. The selection of the variables and the categories within each variable are uniform across the CPES collaborators to allow for maximum comparisons among Asian, black and Latino samples.

Gender is represented by a dummy variable, with males scored 1 and females scored 0. Age of respondent (based on date of birth and date of interview) is a continuous variable that begins from 18 years old. Years in the U.S. is measured as a continuous variable and then split into four categories: less than 5 years, 5-10 years, 11-20 years and 21+ years. Age of immigration is separated into four categories: under 12 years of age; between 13-17 years of age; between 18-34 years of age; and $35+$ years of age.

\subsection{Acculturative Stress (AS)}

The Acculturative Stress scale contains 9 items measuring the stress of culture change that results from immigrating to the United States, which are adapted from the Mexican American Prevalence and Services Survey. ${ }^{[48]}$ Participants are asked in this scale about feeling guilty for leaving behind family and friends (AS1), if they get the same level of respect as they had in their country of origin (AS2), if living in the U.S. has limited their contact with family/friends (AS3), difficulties of interacting with others because of their language (AS4), if they are treated badly because of their language skills (AS5), difficulties of finding work because of ethnicity (AS7), being questioned about legal status (AS8), having concerns of being deported (AS9), and avoiding seeking health services due to fear of immigration officials (AS10). The questions were asked only of respondents who are immigrants (i.e., $0=$ response "no", $1=$ response "yes"). The acculturative stress scale had an internal consistency of $\alpha=0.75$ with the current sample.

As Lueck and Wilson reported, ${ }^{[3]}$ we take the qualitative and quantitative contribution to acculturative stress into consideration, appropriate weightings were assigned to the variables. AS3 was set equivalent with the score 10, AS1 and AS2 with the score 20, AS4 with the score 30, and AS5, AS7, AS8, AS9 and AS10 with the score 40 . Therefore, the highest score was given to those variables that made the highest qualitative and quantitative contribution to the overall construct of acculturative stress. It is measured as a continuous variable, with a higher score equaling more acculturative stress. If a respondent had a summary score of greater than 10, s/he was thought experiencing acculturative stress.

\subsection{Marital Status (MS).}

Respondents were asked to self-report their marital status in a single question (e.g., "Are you currently married, separated, divorced, widowed, or never married?"). Responses were separated into three categories: never married; divorced/separated/widowed; married/cohabiting.

\subsection{Social Position (SOP)}

The Social Position scale uses 7 items to measure the respondent's perceived level of neighborhood availability, accessibility, safety and violence. Participants were asked to state about: if neighborhood can be trusted; generally getting along with each other; would help me if I had an emergency; can look out for each other; I feel safe being out alone in my neighborhood during the night (i.e., $1=$ response "Not at all true", $2=$ Not very true, $3=$ Some what true, 4=Very 
true) ; and to state if neighborhood often get mugged, robbed or attacked; sell or use drugs(i.e., $1=$ response "Very true", 2=Some what true, 3=Not very true, 4=Not at all true).

Summary scores on this measure ranged from 7 to 28 . Higher scores indicated a greater degree of neighborhood availability, accessibility, safety and lower degree of neighborhood violence than lower scores. The Social Position scale had an internal consistency of $\alpha=$ 0.77 with the current sample.

\subsection{English Proficiency(EP)}

English language proficiency is assessed by using the sum of three items "How well do you speak English? How well do you read in English? How well do you write in English?", Possible responses to each item are $1=$ Poor, $2=$ Fair, $3=$ Good, 4=Excellent.

\subsection{Discrimination(DS)}

The Discrimination scale contains 11 items assessing the respondents' experience with everyday discrimination, with a higher score indicating a higher frequency of discrimination. Some examples of everyday discrimination experiences include being disliked (DS4), being treated unfairly (DS5) (i.e., 1=response "Never", 2=rarely, 3 =sometimes, $4=$ often); and include experiencing less courtesy, less respect, poor service, being thought as not smart, other people being afraid of the respondent, being thought as dishonest, being thought as not as good as other people, being insulted, and be threatened/harassed (DS1a-DS1i) (i.e., $1=$ response "Never", 2=Less than once a year, 3=A few times a year, $4=\mathrm{A}$ few times a month, $5=\mathrm{At}$ least once a week, $6=$ Almost every day). The discrimination scale had an internal consistency of $\alpha=0.90$ with the current sample.

\subsection{Family Cohesion(FC)}

The Family Cohesion scale is the sum of 10 items concerning family feelings about spending time together, with a higher score equaling more cohesion. Participants were asked to state family members respect each other (FC1); share similar values and beliefs (FC2); trust and confide in each other (FC4); feel very close to each other (FC9); togetherness is very important (FC10) (i.e., $1=$ response "Strongly disagree", 2=Somewhat disagree, $3=$ Somewhat agree, $4=$ Strongly agree); and to state if too close to their family interfere with their own goals (FC11a); if different customs cause arguments with other family members $(\mathrm{FC} 11 \mathrm{c})$; if feel lonely and isolated because of the lack of family unity (FC11d); if family relationship becoming less important (FC11f); if personal goals in conflict with family (FC11g) (i.e., 1=response "Often", 2=Sometimes, 3=Hardly ever or never). The Family Cohesion scale had an internal consistency of $\alpha=0.92$ with the current sample.

\subsection{Social Networks(SN)}

We uses 12 items to assess the respondents' social life. The items included:

"SN1: How often do you talk on the phone or get together with family or relatives who do not live with you? SN6: How often do you talk on the phone or get together with friends? (Possible responses to each item are $1=$ Less than once a month, $2=$ Once a month, $3=\mathrm{A}$ few times a month, 4=A few times a week, 5=Most every day) SN2: How much can you rely on relatives who do not live with you for help if you have a serious problem? SN3: How much can you open up to relatives who do not live with you if you need to talk about your worries? SN7: How much can you rely on your friends for help if you have a serious problem? SN8: How much can you open up to your friends if you need to talk about your worries? (Possible responses to each item are 1=Not at all, 2=A little, 3=Some, 4=A lot) SN4: How often do your relatives or children make too many demands on you? SN5: How often do your family or relatives argue with you? SN9: How often do your friends make too many demands on you? SN10: How often do your friends argue with you? (Possible responses to each item are $1=$ Often, 2=Sometimes, 3=Rarely, 4=Never) SN12: When you have a problem or worry, how often do you let your (husband/wife/partner) know about it? SN13: When you have a problem or worry, how often do you let someone (else) know about it? $(1=$ Never, $2=$ Rarely, $3=$ Sometimes, $4=$ Most of the time, 5=Always)".

\subsection{Analyses}

There were two stages to the data analysis for men and women separately. Firstly, bivariate correlations were used to examine the relationship and interactive effects between acculturative stress and psychosocial variables (years in the U.S., age of immigration, marital status, social position, English proficiency, discrimination, family cohesion and social networks). Secondly, we fitted two multiple regressions to identify the most significant predictor variables of acculturative stress. Variables did have a significant bivariate correlations with acculturative stress would be included in the regressions. Age was controlled in each set of analyses to compensate for the different age distribution that may be found between male and female respondents.

\subsection{Results}

Among all respondents $(N=1639)$, about $15.5 \%$ reported they feel guilty about leaving family or friends in country of origin; $21.6 \%$ did not perceive the same respect in the U.S. as in country of origin; $36.6 \%$ felt that living out of the country of origin has limited their contact with family or friends; $35.9 \%$ found it hard to interact with other people in English language; 25.3\% reported being treated badly due to poor or accented English; $24.5 \%$ found it difficult to find a job due to Asian descent; $15.3 \%$ worried about their legal status. 
The above findings have suggested that most acculturative stress comes from limited contact with family/friends and limited English language proficiency.

According to the acculturative stress score, 1114 (about $68.0 \%$ ) of the 1639 respondents experienced acculturative stress including 597 (about 68.8\%) women and 517 (about 67.0\%) men.

The bivariate relationships between acculturative stress and psychosocial variables were shown in Table 1. It showed that acculturative stress was correlated significantly with marital status $(r=-0.09, \mathrm{p}<0.05)$ for

Table 1: Bivariate Intercorrelations Between Acculturative Stress and Psychosocial Variables (NLAAS-Asians)

\begin{tabular}{ccccccccc}
\hline Variables & Yrs & Ageim & MS & EP & DS & FC & SOP & SN \\
\hline $\begin{array}{c}\text { (Female } \\
\begin{array}{c}\text { Group) } \\
\text { AS }\end{array}\end{array}$ & & & & & & & & \\
& $-0.14^{* *}$ & $0.15^{* *}$ & -0.05 & $-0.29^{* *}$ & $0.22^{* *}$ & $-0.08^{*}$ & $-0.12^{* *}$ & $-0.16^{* *}$
\end{tabular}

(Male Group)

AS $\quad-0.12^{* *} \quad 0.22^{* *} \quad-0.09^{*} \quad-0.33^{* *} \quad 0.25^{* *} \quad-0.12^{* *} \quad-0.21^{* *} \quad-0.15^{* *}$

Note. $\mathrm{AS}=$ Acculturative Stress; Yrs $=$ Years in the U.S.; Ageim = age of immigration; MS = marital status; $\mathrm{EP}=$ English Proficiency; Sop = Social Position; FC = Family Cohesion; $\mathrm{DS}=$ Discrimination; $\mathrm{SN}=$ Social Networks. $\quad * P<0.05 ; \quad * * P<0.01$

Table 2 represents the beta weights of the correlates that resulted from the analyses conducted at the second stage. Two multiple regression analyses were used to determine the usefulness of correlates in predicting for acculturative stress separately for women and men. The multiple regression model for the female sample resulted in a multiple $R$ of $0.45(F=30.57, p<0.001)$, and the adjusted $R^{2}$ indicated that $19 \%$ of variability in the acculturative stress of female Asian American immigrants could be explained by three of the correlated variables: years in the U.S., English proficiency, and discrimination. For women, age of immigration, family cohesion, social position and social networks do not contribute substantially to the prediction of acculturative stress.

The multiple regression models for the male sample resulted in a multiple $R$ of $0.50(F=31.28, p<0.001)$, and the adjusted $R^{2}$ indicated that $25 \%$ of variability in the acculturative stress of male Asian American immigrants could be explained by seven of the correlated variables: Table 2: Summary of the Multiple Regression Results on Predictors of Acculturative Stress (NLAAS-Asians)

\begin{tabular}{llllll} 
Table 2: & \multicolumn{6}{c}{ Ummary of the Multiple Regression Results on Predictors of Acculturative Stress (NLAAS-Asians) } \\
\hline (Female Sample) & B & SE & Beta & T & Sig. \\
Years in the U.S. & -4.130 & 1.436 & -0.094 & -2.877 & 0.004 \\
Age of immigration & 1.361 & 1.950 & 0.026 & 0.689 & 0.485 \\
English Proficiency & -5.410 & 0.587 & -0.349 & -9.220 & 0.000 \\
Discrimination & 2.332 & 0.252 & 0.323 & 9.247 & 0.000 \\
Family Cohesion & -0.425 & 0.487 & -0.031 & -0.889 & 0.374 \\
Social Position & -0.338 & 0.455 & -0.024 & -0.743 & 0.457 \\
social networks & -0.256 & 0.325 & -0.027 & -0.788 & 0.431 \\
(Male Sample) & & & & & \\
Years in the U.S. & -3.794 & 1.635 & -0.083 & -2.320 & 0.021 \\
\hline
\end{tabular}

male group, but acculturative stress was not substantially correlated with marital status $(\mathrm{r}=-0.05, \mathrm{p}>0.05)$ for female group. Results indicated that higher acculturative stress was significantly correlated to limited years in the U.S., older age of immigration, lower level of English proficiency, more discrimination, less family cohesion, lower social position and less social networks for both women and men. But higher acculturative stress was significantly correlated to "married or cohabiting" marital status only for men. years in the U.S., age of immigration, English proficiency, discrimination, marital status, family cohesion and social position.

We found that gender similarities and differences in the predictors of acculturative stress. For both men and women, longer years in the U.S., higher English proficiency, and less perceived discrimination were related to less acculturative stress. Compared with women, age of immigration, marital status, family cohesion and social position were additional significant correlates of acculturative stress among immigrant men. Social networks was not predictor for both men and women.

\section{DISCUSSION}

This study supports and extends previous research on acculturative stress in immigrant Asian Americans by focusing on gender differences in the psychosocial predictors of acculturative stress. Consistent with our expectations, the psychosocial predictors of acculturative stress are different for men and women. Several important findings emerged from this investigation and reveal the risk factors of acculturative stress across gender. 


\begin{tabular}{lccccc}
\hline Age of immigration & 6.084 & 2.177 & 0.115 & 2.795 & 0.005 \\
Marital status & -4.649 & 2.353 & -.074 & -2.176 & 0.039 \\
English Proficiency & -5.101 & 0.601 & -0.304 & -8.485 & 0.000 \\
Discrimination & 2.096 & 0.242 & 0.303 & 8.657 & 0.000 \\
Family Cohesion & -1.042 & 0.545 & -0.066 & -2.310 & 0.026 \\
Social Position & -1.385 & 0.497 & -0.096 & -2.788 & 0.005 \\
social networks & -0.285 & 0.350 & -0.028 & -0.814 & 0.416
\end{tabular}

Note: Female Sample. $F(7,867)=30.570, \quad p<0.001, \quad$ Multiple $R=0.446, \quad R^{2}=0.199, \quad$ adjusted $R^{2}=0.193$

Male Sample. $\quad F(8,770)=31.287, \quad p<0.001, \quad$ Multiple $R=0.497, \quad R^{2}=0.247, \quad$ adjusted $R^{2}=0.239$

Firstly, results showed that longer years in the U.S., higher English proficiency, and less perceived discrimination were related to less acculturative stress among both female and male groups. This finding supports previous researches that suggest the relationship between acculturative stress and multiple factors ${ }^{[34]}$. Longer years in the U.S. can be seen as a measure of the developmental context in which immigrants arrive in this country. As suggested earlier, immigrants who have lived in the U.S. longer have more opportunity to obtain higher English proficiency, become acculturated, and gain socio-economic status. ${ }^{[38]}$ So longer years in the U.S. predict significantly to less acculturative stress for Asian immigrants.

The present findings indicated that English language proficiency was one of the strongest predictors of acculturative stress in immigrant Asian Americans. English proficiency may provide a buffer against acculturative stressors. The inability to speak English can negatively affect the adjustment of Asian immigrants, which leads to higher levels of acculturative stress.

In addition, perceived discrimination is also a risk factor of acculturative stress. The association of higher acculturative stress with more experience of discrimination (based on ethnicity, race, or cultural background) may suggest that exposure to discrimination may be an important stressor during the acculturation among Asian immigrants. Thus, it is imperative to intervene with discrimination at all levels in order to reduce and avoid stress.

Secondly, Asian men showed a different pattern in the psychosocial predictors of acculturative stress from women. Compared with female groups, the additional psychosocial variables are age of immigration, marital status, family cohesion and social position which significantly predict acculturative stress only for men. When the variable of age controlled, there is no additional variable (among all eight psychosocial variables we examined) significantly predict acculturative stress only for women.

Even though the link between age of immigration and its mechanisms were generally under researched, our present study found that younger age of immigration could predict significantly less acculturative stress for men, but not for women. These associations of age of immigration and acculturative stress might be explained as follows: immigrants arriving as children have an easier time learning English and schools serve as the primary socialization institution outside of the family. On the other hand, immigrants coming as older adults will have a more difficult time learning English and will have fewer opportunities to develop social relationships outside of their families. Traditional Asian values regarding these opportunities are more important for men than women. ${ }^{[25]}$ This also can explain why higher social position as a marker for more opportunity, achievement, socio-economic status appeared to decrease acculturative stress in immigrant men only.

Marital status appeared to be one of the most stable predictors of acculturative stress for Asian men, but not for women. We found that single men were more likely to experience acculturative stress than married or cohabiting men, suggesting that single men may have some disadvantages in the process of cross-cultural adjustment in the U.S. And, "single" marital status might increase men's acculturative stress, but not for women. The fact that men were also more likely to be married or cohabiting at the time of migration to obtain more affectional support of a family network, While the burden of keeping the family together frequently falls on married women. ${ }^{[43]}$ Future studies should consider the potential explanations for these results.

A surprising gender difference is found in family factors. Inconsistent with our expectations, less family cohesion results in more acculturative stress among men only, while this is not the case for women. In Asian culture, girls are not granted as many privileges/freedoms and are assigned more household responsibilities as compared to boys. So women have more obligations and responsibilities in childrearing, family management, and cultural and financial matters. However, Asian men are traditionally expected to be the bread winner who would experience more stress during the process of migration, because Asian Americans have been found to a higher poverty rate than non-Hispanic Whites, to live in geographic areas with a higher cost of living, and to have more family members contributing to the family income. ${ }^{[4]}$ Sue pointed out in the case of Asian Americans a largely "model minority" view has been dominant, justified by references to the higher family incomes, and family stability (i.e., low divorce rates). ${ }^{[50]}$ So Asian Americans men may need more family support than women. Additionally, men's lack of emotional expressiveness and minimal self-disclosure prevent them from seeking family cohesion. Thus, family cohesion may be a more salient and potent variable for Asian men. Short of family cohesion appears 
to be an important risk factor of acculturative stress for them.

Thirdly, the results also showed that social network was not predictor for both Asian American men and women, although social networks is always a risk factor of acculturative stress among immigrants in Canadian and other culture. ${ }^{[43]}$ As mentioned above, family support is a core feature of Asian culture and has traditionally been important in providing emotional support for its members. Because of the great emphasis on harmony and family integration in many Asian cultures, family cohesion may reduce acculturative stress caused by lack of social networks. The interactive influences and mechanisms between family cohesion and social network in the risk for acculturative stress at the time of migration should be considered in the future studies.

Our findings indicated the importance of understanding the causes and effects of acculturative stress. Future studies should consider gender as an important factor in specifying the association between acculturative stress and its predictors. Besides, we recommend that future research should not only look at current conditions in the U.S in its relationship to acculturative stress, but also at the context of exit and its long term effects.

We limited our investigation to several predictor variables that were prominently discussed in the literature. Other unexamined variables may show influence on acculturative stress as well. The task in future studies is to determine more precisely the causes of acculturative stress and the factors that are more universal in nature and those that are more specific to particular groups (e.g., different ethnicities, gender, circumstance of migration).

\section{Acknowledgements}

This research was financially supported by Jiangxi Provincial planning of social science project(16JY29) and Jiangxi Provincial planning of educational science project(15YB006).

\section{References}

1. Berry, J.W and Kim U et al. Comparative studies of acculturative stress. International Migration Review,vol.21, pp.491-511,1987.

2. Constantine, M. G., Okazaki, S and Utsey, S. O. Self-concealment, social self-efficacy, acculturative stress, and depression in African, Asian, and Latin American international college students. American Journal of Orthopsychiatry, vol.74, pp.230-241, 2004.

3. Lueck. K and Wilson. M. Acculturative stress in Asian immigrants: The impact of social and linguistic factors. International Journal of Intercultural Relations, vol.34(1), pp.47-57, 2010.

4. Kuo, B.C. H and Roysircar, G. Predictors of acculturation for Chinese adolescents in Canada: Age of arrival, length of stay, social class, and
English reading ability. Journal of Multicultural Counseling and Development, vol.32,pp. 143-154, 2004.

5. Uppaluri, C. R., Schumm, L. P and Lauderdale, D. Self-reports of stress in Asian immigrants: Effects of ethnicity and acculturation. Ethnicity \& Disease, vol.11, pp.107-114, 2001.

6. Choi, C.Acculturative stress, social support, and depression in Korean American families. Journal of Family Social Work, vol.2(1),pp. 81-97,1997.

7. Liebkind, K. Acculturation and stress: Vietnamese refugees in Finland. Journal of Cross-Cultural Psychology, vol.30,pp. 552-559, 1996.

8. Sandhu, D. S and Asrabai, B. R. Development of an acculturative stress scale for international students: Preliminary findings. Psychological Reports, vol.75, pp.435-448, 1994.

9. Smart, J. F and Smart, D. W. Acculturative stress: The experience of the Hispanic immigrant.The Counseling Psychologist,vol. 23, pp. 25-42, 1995.

10. Hovey, J. D and Magana, C. G. Exploring the mental health of Mexican migrant farm workers in the Midwest: Psychosocial predictors of psychological distress and suggestions for prevention and treatment. The Journal of Psychology, vlo.136,pp. 493-513, 2002.

11. Hwang, W. C and Ting, J. Y. Disaggregating the effects of acculturative stress and acculturative stress on the mental health of Asian Americans. Cultural Diversity and Ethnic Minority Psychology,vol.14(2), pp.147-154, 2008.

12. Poyrazli, S., Kavanaugh, P. R., Baker, A and Al-Timimi,N. Social support and demographic correlates of acculturative stress in international students. Journal of College Counseling, vlo.7, pp.73-82,2004.

13. Williams, C. L and Berry, J. W. Primary prevention of acculturative stress among refugees: Application of psychological theory and practice. American Psychologist, vol.46, pp.632-641, 1991.

14. Thomas, M and Choi, J. B. Acculturative stress and social support among Korean and Indian immigrant adolescents in the United States. Journal of Sociology \& Social Welfare, vol.18(2), pp.123-143, 2006.

15. Lin, N., Ye, X and Ensel, W. M. Social support and depressed mood: a structural analysis. Journal of Health and Social Behavior, vol.40(4), pp.344-359,1999.

16. Shen, B. J and Takeuchi, D. T. A structural model of acculturation and mental health status among Chinese Americans. American Journal of Community Psychology, vol.29 (3), pp.387-418, 2001.

17. Sonderegger, R and Barrett, P. M. Patterns of cultural adjustment among young migrants to Australia. Journal of Child and Family Studies, vol.13(3), pp.341-356, 2004. 
18. Berry, J.W and Anis, R. C. Acculturative stress: The role of ecology, culture and differentiation. Journal of Cross-Cultural Psychology,vol. 5, pp.382-406, 1974.

19. Marcos, L. R. Bilinguals in psychotherapy: Language as an emotional barrier. American Journal of Psychotherapy, vol.30, pp.552-559, 1976.

20. Ward, C and Kennedy, A. Acculturation strategies, psychological adjustment, and socio-cultural competence during cross-cultural transitions. International Journal of Intercultural Relations, vol.18, pp.329-343, 1994.

21. Lee, J., Koeske, G. F and Sales, E. Social support buffering of acculturative stress: a study of mental health symptoms among Korean international students. International Journal of Intercultural Relations, vol. 28, pp.399-414, 2004.

22. Park, So-Youn. Socio-cultural factors related to alcohol use among Asian Americans(Doctoral dissertation, New York University). Dissertation Abstracts International, vol.11, pp.41-82, 2011.

23. Castillo, L. G., Cano, M. A., Chen, S. W., Blucker, R. T and Olds, T. S. Family conflict and intragroup marginalization as predictors of acculturative stress in Latino college students. International Journal of Stress Management, vol.15(1), pp.43-52, 2008.

24. Xiao, S.R., Xu,G.X and Sue, S. Levels and correlates of acculturative stress among immigrant Asian Americans. Chinese Journal of Clinical Psychology, vol.18(6), pp.756-759, 2010.

25. Park, W. Acculturative stress, parental attachment, self-esteem, social support, and psychological adjustment among Korean adolescents in the US.Unpublished doctoral dissertation, University of South Carolina, Columbia, 2000.

26. Poppitt, G and Frey, R. Sudanese adolescent refugees: acculturation and acculturative stress. Australian Journal of Guidance \& Counselling, vol.17(2), pp.160-181, 2007.

27. Graham, M. A. Acculturative stress among Polynesian, Asian and American students on the Brigham Young University-Hawaii campus. International Journal of Intercultural Relations, vol.7(1), pp.79-103, 1983.

28. Gtaic. Psychological traumas and depression in a sample of Vietnamese people in the United States. Health and Social Work, vol.18, pp.184-194, 1993.

29. Takeuchi, D. T., Zane N., Chae, D. H., Gong F., Walton E., Sue, S and Alegria, M. Immigration and Mental Disorders among Asian Americans. American Journal of Public Health, vol.97(1), pp.84-90, 2007.

30. Liebkind, K. A and Jasinskaja-Lahti, I. The influence of experiences of discrimination on psychological stress: A comparison of seven immigrant groups. Journal of Community \& Applied Social Psychology,vol. 10, pp.1-16, 2000.
31. Mena, F. J., Padilla, A. M and Maldonado, M. Acculturative stress and specific coping strategies among immigrant and later generation college students. Hispanic Journal of Behavioral Sciences, vol.9, pp.207-225, 1987.

32. Mak, A. S and Nesdale, D. Migrant distress: the role of perceived racial discrimination and coping resources. Journal of Applied Social Psychology, vol.31,pp.2632-2647, 2001.

33. Duru, E and Poyrazli, S. Personality dimensions, psychosocial-demographic variables, and English language competency in predicting level of acculturatitve stress among Turkish international students.International Journal of Stress Management, vol.14, pp.99-110, 2007.

34. Berry, J. W. Acculturation: Living successfully in two cultures. International Journal of Intercultural Relations, vol.29,pp. 697-712, 2005.

35. [35] Padilla, A. M., Alvarez, M and Lindholm, K. J. Generational status and personality factors as predictors of stress in students. Hispanic Journal of Behavioral Sciences, vol.8, pp.275-288, 1986.

36. Mak, W.W.S, Chen, S.X., Wong, E.C and Zane, N. W.S. Psychosocial model of stress-distress relationship among Chinese Americans. Journal of Social and Clinical Psychology,vol.24,pp.422-444, 2005.

37. Sue, D.W and Sue, S. Counseling the culturally diverse: Theroy and practice(4th ed.). New York: John Wiley \& Sons, 2003.

38. Neto, F. Social adaptation difficulties of adolescents with immigrant backgrouds. Social Behavior and Personality,vol. 30, pp.335-346, 2002.

39. Nwadiora, E and McAdoo, H. Acculturative stress among Amerasian refugees: Gender and racial differences. Adolescence, vol. 31, pp.477-487, 1996.

40. Hiott, A., Grzywacz, J., Arcury, T and Quandt, S. Gender differences in anxiety and depression among immigrant Latinos. Families, Systems \& Health: The Journal of Collaborative Family Health Care, vlo.24, pp.137-146, 2006.

41. Aranda, M., Castaneda, I., Lee, P and Sobel, E. Stress, social support and coping as predictors of depressive symptoms: Gender differences among Mexican Americans. Social Work Research, vol.25, pp.37-48, 2001.

42. Ying, Y.W. (2005). Variation in acculturative Stressors over time: A study of Taiwanese students in the United States. International Journal of Intercultural Relations, vol.29, pp.59-71, 2005.

43. Beiser, M., Barwick, C., Berry, J.W., et al. After the door has been opened: mental health issues affecting immigrants and refugees. Ottawa: Departments of Multiculturalism and Health and Welfare, 1998. 
44. Zuckerman, D. M. Stress, self-esteem, and mental health: How does gender make a difference? Sex Roles, vol.20, pp.429-444, 1989.

45. McGinley, M., Carlo, G., Crockett, et al. Stressed and helping: The relations among acculturative stress, gender, and prosocial tendencies in Mexican Americans. The Journal of Social Psychology, vol.150, pp.34-56, 2010.

46. Alegria M., Takeuchi D., Canino G., Duan N., Shrout P., Meng X-L et al. Considering context, place and culture: the National Latino and Asian American Study. International Journal of Methods in Psychiatric Research, vol.13(4), pp.208-220,2004.

47. Heeringa, S. G., Wagner, J., Torres, M., et al. Sample designs and sampling methods for the Collaborative Psychiatric Epidemiology Studies (CPES). International Journal of Methods in Psychiatric Research.,vol. 13(4), pp.221-240, 2004.

48. Vega, W. A., Kolody, B., Aguilar-Gaxiola, S., Alderete, E., Catalano, R., \& Caraveo-Anduaga, J. Lifetime prevalence of DSM-III-R psychiatric disorders among urban and rural Mexican Americans in California. Archives of General Psychiatry, vol.55, pp.771-778, 1998.

49. Leong, F. T and Okazaki, S. History of Asian American psychology. Cultural Diversity \& Ethnic Minority Psychology,vol.15, pp.352-362, 2009.

50. Sue, S. Ethnic Minority Psychology: Struggles and Triumphs. Cultural Diversity and Ethnic Minority Psychology, vol.15 (4), pp.409-415, 2009. 